Kroezen, M., Hoegaerden, M. van, Batenburg, R. The joint action on health workforce planning and forecasting: results of a European programme to improve health workforce policies.

Health Policy: 2018, 122(2), 87-93

\begin{tabular}{|l|l}
$\begin{array}{l}\text { Postprint } \\
\text { Version }\end{array}$ & 1.0 \\
\hline Journal website & http://www.healthpolicyirnl.com/article/S0168-8510(17)30341-X/fulltext \\
\hline Pubmed link & $\underline{\text { https://www.ncbi.nlm.nih.gov/pubmed/29241846 }}$ \\
\hline DOI & 10.1016/j.healthpol.2017.12.002
\end{tabular}

This is a NIVEL certified Post Print, more info at http://www.nivel.eu

\title{
The Joint Action on Health Workforce Planning and Forecasting:Results of a European programme to improve health workforcepolicies
}

\author{
MARIEKE KROEZEN $^{\mathrm{A}, \boldsymbol{*}}$, MICHEL VAN HOEGAERDEN $^{\mathrm{A}, \mathrm{B}}$, RONALD BATENBURG $^{\mathrm{C}}$ \\ A KU Leuven Institute for Healthcare Policy (LIGB), University of Leuven, Kapucijnenvoer 35 \\ blok d - bus 7001, 3000 Leuven, Belgium \\ B Federal Public Service Health, Food Chain Safety and Environment (Belgium), Eurostation \\ II, 40/10, 1060 Brussels, Belgium \\ C Netherlands Institute for Health Services Research (NIVEL), PO Box 1568, 3500 BN \\ Utrecht, The Netherlands
}

\begin{abstract}
A B S T R A C T
Health workforce (HWF) planning and forecasting is faced with a number of challenges, most notably alack of consistent terminology, a lack of data, limited model-, demand-based- and future-based planning,and limited inter-country collaboration. The Joint Action on Health Workforce Planning and Forecasting(JAHWF, 2013-2016) aimed to move forward on the HWF planning process and support countries intackling the key challenges facing the HWF and HWF planning. This paper synthesizes and discusses theresults of the JAHWF. It is shown that the JAHWF has provided important steps towards improved HWFplanning and forecasting across Europe, among others through the creation of a minimum data set forHWF planning and the 'Handbook on Health Workforce Planning Methodologies across EU countries'. At thesame time, the context-sensitivity of HWF planning was repeatedly noticeable in the application of thetools through pilot- and feasibility studies. Further investments should be made by all actors involved tosupport and stimulate countries in their HWF efforts, among others by implementing the tools developedby the JAHWF in diverse national and regional contexts. Simultaneously, investments should be made inevaluation to build a more robust evidence base for HWF planning methods.
\end{abstract}

\section{INTRODUCTION}

Health workforces are crucial for the sustainability of health sys-tems as there can be no health without a workforce [1]. Yet manyEuropean countries are faced with health 
Kroezen, M., Hoegaerden, M. van, Batenburg, R. The joint action on health workforce planning and forecasting: results of a European programme to improve health workforce policies. Health Policy: 2018, 122(2), 87-93

workforce shortages. Itis estimated that by 2020 there will be a shortfall of one millionhealth workers in Europe [2,3], although it should be noted thatthis number is somewhat out-dated and the underlying calcula-tions are subject to debate [4]. Expected shortages are particularlycritical for certain health professions and specialisations, includingnursing, elderly care and general practice. In addition, almost allEuropean countries are faced with geographical maldistributionsof health professionals, mostly expressed by an undersupply inrural and sparsely populated areas and oversupply in some urbanareas $[2,5,6]$. The shortage of health workers is compounded bythe fact that their skills, competencies and expectations are often not optimally suited to meet changing population health needs[7,8]. Moreover, health reforms, taking place in many countries,also change the legal and institutional context of health professions. Given these challenges, human resource planning in the health sec-tor, or health workforce planning, emerges as a key tool to addressthem [9].

\subsection{Health workforce planning}

Health workforce planning is concerned with ensuring that theright number of people, with the right skills, are at the right placeat the right time to deliver the right services to those in need ofthem [10]. The main aim of planning is to achieve an optimal bal-ance of demand and supply of health workers in both the shortand long term [11]. To achieve this aim, forecasting is an impor-tant part of the planning process. Yet despite its importance, thereis no agreed definition or single accepted approach to forecastinghealth workforce requirements [12]. In this paper, we understandforecasting as a scientific based and policy driven methodology.Forecasting workforces requires multiple steps: to predict severalalternative futures, decide which is most probable or desirable, and then plan for that selected future by factoring in particular forces, such as political climate and resources [13]. It is important to stress that forecasts are not projections. A projection takes current con-ditions, develops scenarios by 'educated guesses' about possible future changes, and looks at the implications of those changes. In contrast, forecasting explicitly aims to define what the future will hold and requires theory and hypothesis about the mechanisms behind these potential futures [14].

\subsection{Aim of this paper}

The aim of this paper is to synthesize and discuss the results of an EU initiative - the Joint Action on Health Workforce Plan-ning \& Forecasting - set up to support and stimulate country efforts in health workforce development. The paper in particular focuses on five key findings of the JAHWF, related to the most severe cur-rent challenges in HWF planning, i.e. planning terminology, data availability, modelbased planning, future-based planning and col-laboration.

\subsection{Challenges in health workforce planning}

In a time of budget restraints, workforce shortages and changing health care needs, health workforce planning is more important than ever, but at the same time it is getting increasingly complicated [10,11]. The main difficulties facing health workforce planning and forecasting are of methodological as well as strategic nature, and are summarized below:

\subsubsection{Lack of consistent terminology}


Kroezen, M., Hoegaerden, M. van, Batenburg, R. The joint action on health workforce planning and forecasting: results of a European programme to improve health workforce policies. Health Policy: 2018, 122(2), 87-93

To make an accurate calculation of the stock and flow of health workforces, systematic and consistent definitions are required. Definitions enable data and information collected from different sources (e.g. from public and private sector, professional registries, labour force surveys, etc.) to become comparable and to be used consistently in models and calculations. Currently, within and between countries, there is severe inconsistency and heterogene-ity in the definitions that are being used for health professions and the general terminology surrounding health labour market indi-cators $[10,15]$. For example, there may be differences in health professionals' status; some numbers may refer to 'practising pro-fessionals' (i.e. professionals that provide a service directly to the public), while others may refer to the 'professionally active' (i.e. professionals that completed an education as a prerequisite for the job). A prerequisite to feed and interpret health workforce models and forecasting is to have uniform definitions of both the units of analysis and the factors or parameters that are included in the models.

\subsubsection{Lack of data}

Recent data on the number of active health care workers and their distribution in the health system are a key requirement for health workforce planning [11]. Yet these information systems are lacking in numerous countries, representing one of the main obsta-cles to effective health workforce planning $[9,10,16]$. For example, in many European countries data on number of health workers and trainees, their specialisation, their geographical spread, age, gender and country of provenance are not or partly available, dif-ficult to gather or not registered. A specific challenge for health workforce planning is the lack of data on cross-border and cross-sectoral mobility of health professionals; to quantify where health workers go, how long they stay away and whether they come back or not $[17,18]$. Accurate data about the migration of health work-forces is not available in many European countries. A deficit which is compounded by the fact that there is no single definition of health professional mobility in place [10]. One way to cope with the lack of data on health workforces, as a first step, is to mobilize data collection and analysis on a limited number of indicators that are available, comparable and measur-able using standard data sources. There is, however, no guideline or agreement on what these 'minimum data requirements' for health workforce planning should look like [10].

\subsubsection{Limited model and demand-based health workforce planning}

Currently, there appear to be few countries that engage in model based health workforce planning [19]. In some countries where national health workforce planning institutions are in place, quan-titative tools or models are used to develop projections and/or forecasts of the required future workforce [10]. In general, three approaches can be discerned in these types of health workforce planning models [10,11]: - The supply-based approach, which focuses on balancing health workforce inflow (e.g. graduates, immigrant health workers), outflow (e.g. health workers who emigrate or retire) and the activity rates of the currently active health workers (measured in either headcounts or FTE). $\bullet$ The demand-based approach, which focuses on the current and future demand for health services (estimated from the popula-tion composition, demography, and health service utilization), and therefrom 
Kroezen, M., Hoegaerden, M. van, Batenburg, R. The joint action on health workforce planning and forecasting: results of a European programme to improve health workforce policies.

Health Policy: 2018, 122(2), 87-93

the required capacity of health workers. • The needs-based approach, which extends the demand-based approach by additionally considering epidemiological and socialcultural factors. Looking at the evidence that is available, the large majority of European countries that engages in model based workforce plan-ning takes a supplybased approach and does not take into account the actual health needs of the population. Only a minority of countries incorporates a demands-based or needsbased approach in their model [10]. Also, many countries have a partial or 'silo' approach of planning separate health professions and ignoring rela-tionships between health professions [20]. This limits the accuracy of planning models and restricts their potential impact. It has been noted that more sophisticated and integrated models of workforce planning that cut across different professional groups and take into account more factors, such as skill mix and working practices, seem to offer a better prospect of contributing to the sustainability of health systems. Finally, it can be concluded that very few health workforce planning models are or have been empirically evaluated, limiting the possibilities for assessment of the quality and impact of the various models on health workforces and health system per-formance [11]. There are various reasons why so few countries engage in model-based and demand-based health workforce planning. One reason is that it is difficult to incorporate the variables that deter-mine the future supply and demand of workers, mainly due to the earlier mentioned lack of reliable data on these variables [11]. Apart from the methodological challenges, there are also strategic issues that need to be tackled for planning models to be initiated and implemented. This includes ensuring that the required capacity and skills for health workforce planning are sufficiently trained and available within institutions or departments in charge of workforce planning [10].

\subsubsection{Limited future-based planning and use of qualitative methods}

While planning the required numbers and types of health professionals to sustain the current distribution is a challenge, estimating the required skills and competences of the HWF for the future is an even greater challenge. Comprehensive health workforce modelling and forecasting is complex and fraught withpitfalls [21]. Currently, no country matches and forecasts the needs, demand and supply of its health workers in a manner that can bereferred to as "best practice" [8]. European countries are invest-ing in better estimates to model their current and future healthworkforce requirements. Needs-based models are extended, forexample, with information on trends in risk factors and the inci-dence/prevalence of different diseases to improve estimates offuture care needs and the required health workforce [11]. This isoften based on qualitative data collection through interviews andworkshops with national experts in these areas [22]. Yet complexand challenging methodological and technical problems remain.Again, it should be noted that the current state of most countrydatabases is generally inadequate to allow for a reliable analysisof the available and required qualitative and quantitative healthworkforce capacity [8]. Hence, needs-based models are inherentlylimited and/or need to draw on expectations with high uncertain-ties and normative judgments, for example about what type andlevel of care is really required [11].

\subsubsection{Limited international collaboration in health workforceplanning}


Kroezen, M., Hoegaerden, M. van, Batenburg, R. The joint action on health workforce planning and forecasting: results of a European programme to improve health workforce policies.

Health Policy: 2018, 122(2), 87-93

Finally, while some countries take into account the health labourmarket situation of their neighboring countries, or explore regionalborder policies, the possibilities for countries to collaborate arelargely underutilized. There is scope for increased collaborationand exchange of good practice in HWF planning between Europeancountries, increasing the possibilities to support the developmentof national HWF policies for the future [15].

\subsection{The Joint Action on Health Workforce Planning \& Forecasting}

In order to support EU Member States to tackle the key chal-lenges facing the health workforce and health workforce planning,the European Commission funded a feasibility study on EU levelcollaboration on health workforce needs [10,23]. Based on the out-comes of the feasibility study, the Commission decided to fund aJoint Action on Health Workforce Planning \& Forecasting (JAHWF)under the Health Programme (2008-2013). Coordinated by theBelgian Ministry of Health, the three year programme of work(2013-2016) involved 30 associated partners and 62 collabora-tive partners, representing countries and stakeholder groups fromacross Europe [24]. The focus of the JAHWF was restricted to doc-tors, nurses, pharmacists, dentists and midwives for two reasons.First, where planning models are available, they usually focus onone or more of these five professions. Second, these are the five pro-fessions with automatic recognition under Directive 2005/36/EC,making them especially relevant where mobility issues are con-cerned, and hence for health workforce planning.The general objective of the Joint Action on Health WorkforcePlanning \& Forecasting was to create a platform for collaborationand exchange between Member States, to move forward on theplanning process and to prepare the future of the health work-force within Europe. More specifically, the JAHWF formulated thefollowing eight objectives:1. Better understanding of terminology2. Better monitoring of the HWF by access to timely data3. Updated information on mobility and migration trends in the EU4. Guidelines on quantitative and qualitative HWF planningmethodology5. Increased quantitative and qualitative planning capacity6. Estimation of future skills and competencies needed in thehealth workforce7. A platform of cooperation to find possible solutions on theexpected shortage of HWF8. A higher impact of HWF planning and forecasts on policy deci-sion makingThe JAHWF was structured in work packages (WPs) [25], whichare further elaborated upon in Appendix 1 in the supplementarymaterial.

\section{METHODS}

The JAHWF adopted a multi-disciplinary theoretical and empiri-cal approach to map, study and improve health workforce planningin Europe. A variety of quantitative and qualitative methodswere used, including literature reviews, survey research, semi-structured interviews and focus group discussions.

Additionally, workshops were organized, bringing together a variety of Europeanand global experts to critically examine and jointly discuss healthworkforce planning and particular challenges. Workshop responseswere analysed qualitatively and incorporated in the final results.Specific initiatives of the JAHWF consisted of two pilot studies inItaly and Portugal to test and apply some of the JAHWF outputs(the 'Handbook on Health Workforce Planning Methodologies acrossEU countries' and the minimum data set). It was studied if theywere effective in improving existing (national) HWF planning sys-tems and what adaptations were necessary. Also, two feasibilitystudies - one in two German states and one jointly in Romaniaand 
Kroezen, M., Hoegaerden, M. van, Batenburg, R. The joint action on health workforce planning and forecasting: results of a European programme to improve health workforce policies.

Health Policy: 2018, 122(2), 87-93

Moldova - explored the opportunities of implementing newplanning methodologies across regions and countries. Another pilotproject in Belgium studied the incorporation of qualitative methodsin the HWF planning process. It is based on this material gatheredduring the Joint Action that key findings on planning terminology,data availability, model-based planning, future-based planning andcollaboration have been extracted. A full methodology descriptionand overview of produced outputs can be found in Appendix 1 inthe supplementary material.

\section{RESULTS}

\subsection{National and international terminology used in healthworkforce planning}

The JAHWF compared the terminology used in HWF planning,both at national and international level, and found considerablegaps and inconsistencies in the terms and definitions that are used.At international level, the OECD/Eurostat/WHO-Europe Joint Ques-tionnaire on Non-Monetary Health Care Statistics aims to serve asa harmonised tool for international reporting on the health work-force, aimed at providing internationally comparable data [26]. Yetwhen comparing the data supplied by EU Member States to the JointQuestionnaire, considerable discrepancies were found in the defi-nitions and interpretations of some of the key Joint Questionnaireterminology. Table 1 summaries the main inconsistencies identi-fied by the JAHWF, broken down by type of professions, activitystatus and activity amount.Hence, the JAHWF concluded that there are considerable dif-ferences between countries in some of the key definitions andinterpretation of factors used in HWF planning. This is confirmed bythe fact that national definitions are not always identical to the def-initions used in the Joint Questionnaire [27]. It was found that thesedifferences can often be traced back to the country-specific featuresof indicators. In the case of federal states or countries with regionalbased HWF planning, even more difficulties can occur due to dif-ferences in terminology used between regions, and/or between theregional and national systems.

\section{[TABLE 1]}

\subsection{A minimum data set for health workforce planning}

The JAHWF identified a number of recurrent challenges amongEU Member States related to data, data sources and methodology.First and foremost, a consistent lack of data was reported. Othercommon challenges identified were related to a lack or misuse ofplanning models and methods, poor data quality and the absence ofqualitative data. The JAHWF developed a minimum data set (MDS) - a limited and essential number of indicators, which are generallycomparable and should be measured regularly with the use of stan-dard data sources - in order to help improve the data availabilityfor health workforce planning. The scope of the MDS was definedas follows: $\bullet$ To recognize the major imbalances in the HWF; $\bullet$ To analyse these imbalances; and•To identify possible solutions. The MDS contains a total of seven indicators, five on the supplyside - labour force, training, retirement, migration (outflow) andmigration (inflow) - and two on the demand side - population andhealth consumption, all to be calculated through eight categoriesof data. Table 2 shows the MDS and data availability across 11 EUMember States (BE, DE, ES, FI, 
Kroezen, M., Hoegaerden, M. van, Batenburg, R. The joint action on health workforce planning and forecasting: results of a European programme to improve health workforce policies. Health Policy: 2018, 122(2), 87-93

GR, HU, IT, NL, PL, PT, SK) and Iceland,each cell containing the number of countries that reported havingthese data available.It becomes clear from Table 2 that most of the twelve countrieshave basic data related to the HWF labour force available, althoughnot specified in FTE (a more complex measure) and the country ofprofessional's first qualification. For other indicators, data availabil-ity is lower and for the migration indicators, especially the outflowof the health workforce, data turn out to be scarcely available.To test the MDS on its practical feasibility, the JAHWF con-ducted two pilot studies (Italy and Portugal) and feasibility studies(Germany and Romania/Moldova). It was shown that the MDS wassometimes partially used or used with some adaptations. For exam-ple in Italy data on specialisation was not available as doctorsare planned as one single professional category. In Portugal, dataon professional activity status was added to distinguish the 'pro-fessionally active' stock from the 'licensed to practice' stock. Yetoverall, the MDS developed by the JAHWF was considered usefulby the pilot and feasibility countries for making simple projections.

\subsection{Key elements of the health workforce planning process}

While having a minimum data set in place is a prerequisite toenable HWF planning, data availability alone does not necessarilylead to successful planning processes. After all, challenges facingHWF planning are not merely methodological of nature, but alsostrategic. To shed light on the planning process, the 'Handbook onHealth Workforce Planning Methodologies across EU countries' [28]identifies five key elements to be included by every planning sys-tem: goals, a forecasting model, data, link to policy actions andorganisation. Table 3 describes each element in more detail.The JAHWF pilot studies and feasibility studies showed thatthese five elements are indeed key and useful to start or improveHWF planning processes. Still, it was noted that especially goal set-ting and links to policy actions are hardly feasible within a limitedtimeframe. Yet added value was demonstrated in creating syner-gies between various bodies and stakeholders to reach goals, whiledeveloping a variety of strategies seemed to increase the chancesof policy actions being turned into sustainable programmes fora sustainable future health workforce. Another important findingwas that some dimensions in forecasting models are better forecasted at local level (e.g. population needs), while others at national(inflows from education) and international level (mobility flows).Finally, the importance of organising a HWF planning process wasemphasised, especially the establishment of a project team with asufficient number of capable staff with various skills.

\subsection{Use of qualitative methods in health workforce planning}

In view of the underuse of qualitative data in HWF planning,the JAHWF has developed guidelines on methods that can be usedto include qualitative data in planning processes. It should benoted that qualitative methods can be used on their own, but arepreferably applied alongside quantitative measures to ensure anintegrated approach to HWF planning. A survey by the JAHFW among 7 EU Member States (BE, DE, ES,FI, HU, NL, UK) and Norway showed that qualitative methods arealready being used, to some extent, to determine how contingentand exogenous factors or changes may influence the supply anddemand of health workers. It was mentioned by survey respon-dents that without qualitative input, HWF forecasting would onlybe based on observable historical data, i.e. "planning for yesterday". Another respondent stated that qualitative data are essential "togenerate or 
Kroezen, M., Hoegaerden, M. van, Batenburg, R. The joint action on health workforce planning and forecasting: results of a European programme to improve health workforce policies. Health Policy: 2018, 122(2), 87-93

validate values used in modelling assumptions whererobust quantitative data is not available'. A continuum of qualitativemethods were listed by the JAHWF ranging from informal (inter-views) to more structured (Delphi exercise). However, no hierarchyof approach can be implied. The six methods are:

-Stakeholder identification and analysis: ensures that all relevantpeople are identified and brought into the HWF planning pro-cess, to contribute to the relevance of outputs, transparency ofdecision-making and developing a shared vision of the HWF.

-Literature review: considers the evidence that is available, andexamine previous research and thinking on a topic.

-Interview: identifies trends, factors and policies that may affectfuture health workforces.

-Survey: gathers information from a large group of respondents.

-Scenario: describes imaginative, plausible and challenging waysthat the future might unfold. -Delphi exercise: obtains expert consensus on a variable, param-eter or factor that is needed in the calculation for subsequentworkforce modelling stages.

\section{[TABLE 2]}

The JAHWF pilot study in Belgium used some of these qualitativemethods, most notably the Delphi exercise, to improve the Belgiangeneral practitioner workforce planning process. It was found thatthe use of the Delphi method improved the GP forecasting modelinputs and outputs by helping to quantify a range of variables.Therefore, this method will be structurally integrated in the BelgianHWF planning approach. While the Belgian experiences were pos-itive, it was noted that the use and selection of any method shouldbe dependent on the situation and context of the study they arebeing used in. Also, some level of expertise is required in applyingthe qualitative methods.

\subsection{Collaboration among European countries in health workforceplanning}

The JAHWF significantly improved collaboration between Euro-pean countries in terms of HWF planning and related processes. TheJAHWF workshops and conferences proved to be a fruitful knowl-edge transfer mechanism, as they allowed country representativesand stakeholders with similar problems to come together and workon specific issues. Further workshops have been organized based onthe JAHWF model, for example a Policy Dialogue on the HWF wasorganized in Brussels in May 2017, bringing together various Mem-ber States at the invitation of Belgium. Also, countries involved inthe JAHWF have helped Italy in its deployment of planning modelsin most Italian regions, which have now been successfully imple-mented. Collaboration remains further intact through the Europeanexpert network on the HWF, which is currently in development.Also, international agencies such as the WHO have structurallyembedded JAHWF results, for example in the development of theNational Health Workforce Accounts [29].

\section{DISCUSSION}

The aim of this paper was to synthesize and discuss the results ofthe Joint Action on Health Workforce Planning \& Forecasting in lightof the current challenges in health workforce planning and fore-casting, i.e. planning terminology, data availability, 
Kroezen, M., Hoegaerden, M. van, Batenburg, R. The joint action on health workforce planning and forecasting: results of a European programme to improve health workforce policies.

Health Policy: 2018, 122(2), 87-93

model-basedplanning and future-based planning and collaboration. From theoverview presented, it becomes clear that the JAHWF has addressedand provided guidance on these challenges, with the creation ofthe minimum data set and 'Handbook on Health Workforce PlanningMethodologies across EU countries' as the two most tangible results.

\section{[TABLE 3]}

Moreover, by taking not only a theoretical but also an empiricalapproach, through the pilot- and feasibility studies, the JAHWF wasable to show that the challenges facing HWF planning and forecast-ing across Europe are substantial but not insurmountable. In doingso, the JAHWF has provided important steps towards improvedHWF planning and forecasting across Europe.Looking at the future, the JAHWF has laid a solid foundation forthe next steps in HWF planning and forecasting by providing thebasic tools and insights to start a planning process. At the sametime, as is often the case in HWF planning and forecasting [11], noformal evaluation of these tools has taken place and the positiveresults from the pilot- and feasibility studies can only be consid-ered indications of effectiveness in solving HWF related problems.Moreover, the context-sensitivity of HWF planning was repeatedlynoticeable in the application of the tools, sometimes even limitingtheir potential impact. In this sense, the JAHWF has drawn atten-tion to the fact that HWF planning and forecasting are mostly anational and local affair and there is not one HWF planning modelor methodological approach which is applicable across all settings. This context-sensitivity is confirmed by the fact that many of thedifferences found in HWF terminology originate from the country-specific nature of indicators. This justifies their use in current format national or even regional level. As was also noted by Ono et al.[11], proper HWF planning needs to go below the national level. A clear national or regional system for terminology, complementedwith accurate data, therefore plays a more important role for HWFplanning than internationally comparable definitions.Furthermore, the JAHWF showed that national and local contextnot only influence the terminology used and the goals of a planningprocess, but also the choice and (full) use of HWF planning meth-ods and tools. This conclusion is supported by earlier studies $[5,30]$ on the different dimensions and determinants of HWF planning.Batenburg [30] concluded that HWF planning is context sensitiveand that the level of model-based planning is strongly related to acountry's type of health labour market or health system. Hence, theidea of a 'golden standard' in HWF planning models and method-ological approaches is neither desirable nor feasible. HWF planningtools should have the flexibility to be adjusted to national and localneeds and country characteristics, especially in the current climateof cutbacks and health system reforms [31]. The JAHWF has pro-vided planning tools at a basic level that allow doing this. Yet sofar, how to improve HWF planning in a context-sensitive manneris little investigated [30]. Experiments with the tools developed bythe JAHWF, such as the minimum data set, in diverse national con-texts may provide more insight into this area. Another interestingavenue for further exploration is the use of country learning clustersin HWF planning and forecasting. To improve context-sensitivity inHWF planning, it may be beneficial to cluster countries - e.g. basedon health care system or primary care strength - that are expectedto learn from each other because they share the same conditionsand starting position for HWF planning [30]. 
Kroezen, M., Hoegaerden, M. van, Batenburg, R. The joint action on health workforce planning and forecasting: results of a European programme to improve health workforce policies.

Health Policy: 2018, 122(2), 87-93

\section{CONCLUSIONS}

When considering the challenges facing health workforce plan-ning, the contribution of the Joint Action on Health WorkforcePlanning and Forecasting can be observed mostly in creating aware-ness and activating countries to consider the more basic planningelements (e.g. by providing a minimum data set). The predic-tion and evaluation of HWF planning, which are more complexand context dependent elements, appear to be a long way off formany countries. Yet through its pilot and feasibility studies, theJAHWF has shown that even though the challenges facing HWFplanning and forecasting across Europe are substantial, they arenot insurmountable. Further investments should be made by allactors involved to support and stimulate countries in their HWFefforts, among others by implementing the tools developed bythe JAHWF, such as the minimum data set and Handbook, indiverse national and regional contexts. Simultaneously, invest-ments should be made in evaluation, staff capacity and expertiseto build a more robust evidence base surrounding HWF planningmethods, especially in the face of growing evidence that HWF plan-ning adds value and should be stimulated in general [11].6. Conflict of interest statementNone of the authors has any potential conflict of interest relatedto this manuscriptAcknowledgementsThe Joint Action on European Health Workforce Planning andForecasting was co-funded by the EU Public Health Programme20082013 (grant agreement no 20122201). The content of thisarticle represents the views of the contractor and is its sole respon-sibility; it can in no way be taken to reflect the views of the EuropeanCommission and/or Chafea or any other body of the EuropeanUnion. The European Commission and/or Chafea do not guaran-tee the accuracy of the data included in this article, nor do theyaccept responsibility for any use made by third parties thereof. Thefunding source had no involvement in the conduct of the study, butapproved of the decision to submit this article for publication. Theauthors wish to thank all associated and collaborating partners ofthe Joint Action on Health Workforce Planning and Forecasting fortheir contributions to the project, without which this article wouldnot have been possible.

\section{Appendix 1 Supplementary data}

Supplementary data associated with this article can be found, inthe online version, at https://doi.org/10.1016/j. healthpol.2017.12.002.

\section{REFERENCES}

[1] Campbell J, Dussault G, Buchan J, Pozo-Martin F, Pozo-Martin M, Leone C, et al.A Universal Truth: No Health without a Workforce. Geneva: World HealthOrganization; 2013.

[2] European Commission. Commission Staff Working Document on an Action Planfor the EU Health Workforce. Strasbourg: European Commission; 2012.

[3] Wismar M, Maier CB, Glinos IA, Bremner JGD, Figueras J. Health ProfessionalMobility and Health Systems in Europe: an Introduction; 2011.

[4] Kuhlmann E, Batenburg R, Groenewegen P, Larsen C. Bringing a European per-spective to the health human resources debate: a scoping study. Health Policy2013;110(1):6-13.

[5] Kroezen M, Dussault G, Craveiro I, Dieleman M, Jansen C, Buchan J, et al. Recruit-ment and retention of health professionals across Europe: a literature reviewand multiple case study research. Health Policy 2015;119(12):1517-28.

[6] Buchan J, Twigg D, Dussault G, Duffield C, Stone P. Policies to sustain thenursing workforce: an international perspective. International Nursing Review2015;62(2):162-70.

[7] Sarkis N, Mwanri L. The role of information technology in strengthening humanresources for health: the case of the Pacific open learning health network. Health Education 2013;114(1):67-79. 
Kroezen, M., Hoegaerden, M. van, Batenburg, R. The joint action on health workforce planning and forecasting: results of a European programme to improve health workforce policies.

Health Policy: 2018, 122(2), 87-93

[8] Dussault G, Buchan J, Sermeus W, Padaiga Z. World Health Organization Copen-hagen: Assessing Future Health Workforce Needs; 2010.

[9] Dubois C, Rechel B, Introduction McKee M. Critical challenges facing the healthcare workforce in Europe2. In: Dubois C-A, Rechel B, McKee M, editors. Thehealth care workforce in Europe: learning from experience. London: EuropeanObservatory on Health Systems and Policies; 2006. p. 1-18.

[10] Matrix Insight Eu Level Collaboration on Forecasting Health WorkforceNeeds, Workforce Planning and Health Workforce Trends-a FeasibilityStudy; 2012. Available at: http://ec.europa.eu/health/workforce/docs/healthworkforce study 2012 report en.pdf (Accessed 31-05-2016).

[11] Ono T, Lafortune G, Schoenstein M. Health Workforce Planning in Oecd Coun-tries; 2013.

[12] Roberfroid D, Leonard C, Stordeur S. Physician supply forecast: better thanpeering in a crystal ball? Human Resources for Health 2009;7(1):1.

[13] Faherty VE. Using forecasting models to plan for social work education in thenext century. Journal of Social Work Education 1997;33(2):403-11.

[14] Kirch DG, Henderson MK, Dill MJ. Physician workforce projections in an era ofhealth care reform. Annual Review of Medicine 2012;63:435-45.

[15] Sermeus W, Bruyneel L. Investing in Europe's Health Workforce of Tomorrow:Scope for Innovation and Collaboration: Summary Report of the Three PolicyDialogues. European Observatory on Health Systems and Policies; 2010.

[16] Rechel B, Dubois C-A, McKee M. The Health Care Workforce in Europe: Learningfrom Experience. World Health Organization; 2006.

[17] Wismar M, Maier CB, Glinos IA, Dussault G, Figueras J. Health professionalmobility and health systems: Evidence from 17 countries. Copenhagen: WHORegional Office for Europe; 2011.

[18] Communities CotE. Green Paper on the European Workforce for Health. Brus-sels: Commission of the European Communities; 2008.

[19] Batenburg R. Health workforce governance and integration: the fit betweenplanning and system. The European Journal of Public Health 2014;24(suppl2):19, cku164.

[20] Bloor K, Maynard A, Hall J, Ulmann P, Farhauer O, Lindgren B. Planning humanresources in health care: towards an economic approach: an international comparative review. Canadian Health Services Research Foundation = Fondationcanadienne de la recherche sur les Services de santé; 2003.

[21] Politzer RM, Hardwick KS, Cultice JM, Bazell C. Eliminating primary care healthprofessional shortage areas: the impact of Title VII generalist physician educa-tion. The Journal of Rural Health 1999;15(1):11-20.

[22] Batenburg R, Lee I, Wiegers T, Velden L. De arbeidsmarkt voor verloskundigenin2012 en 2022/2027: een capaciteitsraming op basis van beleidsrijke scenario's;2013.

[23] European Commission. Improving Workforce Planning and Forecasting; 2016.Available at: http://ec.europa.eu/health/workforce/policy/planning/index en.htm, (Accessed 13.07.2016).

[24] JAHWF. Introductory Information to the Joint Action; 2016. Available at: http://healthworkforce.eu/introductory-information-to-the-joint-action/ (Accessed31-052016).

[25] JAHWF. Joint Action Health Workforce Planning and Forecasting Leaflet; 2014.Available at: http://ec.europa.eu/health/workforce/docs/ev 20140602 leafleten.pdf (Accessed 31-05-2016).

[26] OECD/Eurostat/WHO-Europe. Guidelines for Completing theOECD/EUROSTAT/WHOEurope Questionnaire 2015; 2015.

[27] Girasek E, Kovács E, Aszalós Z, Eke E, Ragány K, Kovács R, et al. Headcount andFTE data in the European health workforce monitoring and planning process. Human Resources for Health 2016;14(1):1.

[28] JAHWF. In: Malgieri A, Michuletti P, Van Hoegaerden M, editors. Handbookon Health Workforce Planning Methodologies Across EU countries. Bratislava:Ministry of Health of the Slovak Republic; 2015. 
Kroezen, M., Hoegaerden, M. van, Batenburg, R. The joint action on health workforce planning and forecasting: results of a European programme to improve health workforce policies. Health Policy: 2018, 122(2), 87-93

[29] WHO. National Health Workforce accounts -A Handbook - Draft for Con-sultation; 2016. Available at: http://www.who.int/hrh/documents/brief nhwahandbook/en/ (Accessed 27.06.2017).

[30] Batenburg R. Health workforce planning in Europe: creating learning countryclusters. Health Policy 2015;119(12):1537-44.

[31] Maresso A, Mladovsky P, Thomson S, Sagan A, Karanikolos M, Richardson E, et al.Economic crisis, health systems and health in Europe. In: Country ExperiencesWHO Europe, European Observatory of Health Systems; 2015.

\section{TABLES}

Table 1

Comparison Joint Questionnaire (JQ) and EU national HWF terminology by the JAHWF.

\begin{tabular}{ll}
\hline Dimension & Inconsistencies at international level \\
\hline Profession & For professional nurses, associate professional nurses \\
and midwives, there is a significant gap between the & ISCO codes used in the JQ and nationally applied \\
definitions and classifications. E.g. the JQ definition of \\
professional nurses and associate professional nurses \\
describes differences in job content and competence, \\
while qualifications are not mentioned. In several \\
countries though, including Finland, Germany, Ireland \\
and the Netherlands, the boundary between the two \\
groups is drawn by qualifications. \\
The three JQ activity status categories (practising, \\
professionally active, licensed to practice) are often not \\
comparable to national and local legal concepts and \\
practices. E.g. in Hungary a health professional has to \\
fulfil the requirements of cPD83 in order to obtain the \\
licence to practice status and thus get into the \\
Operational Registry. The licence has to be renewed \\
every 5 years. In Belgium, the proof of at least two \\
occasions of reimbursement by the NIHDI (National \\
Institute for Health and Disability Insurance) is the \\
criterion to enter the practising MD category. \\
There are significant differences across EU countries in \\
the measurement of full-time equivalent (FTE). E.g. in \\
Finland, FTE is defined as 1.0 for full-time workers and \\
0.6 for part-time workers, while in Spain FTE for men \\
is 0.9 times male headcount, and FTE for women is 0.8 \\
times female headcount.
\end{tabular}


Kroezen, M., Hoegaerden, M. van, Batenburg, R. The joint action on health workforce planning and forecasting: results of a European programme to improve health workforce policies.

Health Policy: 2018, 122(2), 87-93

Table 2

Availability of data to cover the minimum data set for HWF planning in 11 EU Member States ${ }^{\mathrm{a}}$ and Iceland.

\begin{tabular}{|c|c|c|c|c|c|c|c|}
\hline \multirow[b]{2}{*}{ Data to calculate the indicator: } & \multicolumn{5}{|c|}{ Supply indicators ${ }^{b}$} & \multicolumn{2}{|c|}{ Demand indicators ${ }^{c}$} \\
\hline & Labour force & Training & Retirement & Migration (inflow) & Migration (outflow) & Population & Health consumption \\
\hline Profession & 12 & 10 & 9 & 8 & 4 & $N / A$ & $N / A$ \\
\hline Age & 12 & 5 & 7 & 5 & 2 & 11 & 8 \\
\hline Head count & 12 & 10 & 10 & 7 & 4 & 11 & 8 \\
\hline FTE & 7 & $N / A$ & $N / A$ & $N / A$ & $N / A$ & $N / A$ & N/A \\
\hline Geographical area & 11 & 6 & 7 & 5 & 2 & 9 & 7 \\
\hline Specialisation & 11 & 8 & 6 & 6 & 2 & $N / A$ & $N / A$ \\
\hline Country of 1 st qualification & 6 & 3 & 3 & 5 & 2 & $N / A$ & N/A \\
\hline Gender & 10 & $N / A$ & N/A & $N / A$ & $N / A$ & $N / A$ & $N / A$ \\
\hline
\end{tabular}

a Belgium, Finland, Germany, Greece, Hungary, Italy, the Netherlands, Poland, Portugal, Slovakia and Spain. The table aggregates results on data for doctors, nurses, pharmacists, dentists and midwives per country. However, most often data are only available for physicians.

b Labour force: the number of health workers currently producing healthcare (practising); Training: the number of health professionals (headcount) that complete education (basic or specialist) per year; Retirement: forecast of the number of professionals (headcount and full time equivalent) that will retire each year; Migration (inflow): forecast of the number of licensed and recognised health professionals (headcount) that may enter the country, calculated using average flow numbers in recent years; Migration (outflow): forecast of number of practising professionals (headcount) that may leave the country, calculated using the average flow numbers in recent years.

c Population: number of current inhabitants, by age group; Health consumption: the total health consumption in year $\mathrm{x}$, by age group.

Table 3

Five key elements of the health workforce planning process ${ }^{\mathrm{a}}$.

\begin{tabular}{ll}
\hline Element & Content \\
\hline Goals & Setting objectives, communication of the goals, \\
timeframe, etc. & Mathematical forecasting model, quantitative \\
& and qualitative methods, scenario analysis, \\
& projection period, frequency of updating, \\
& migration flows, segmentation of future \\
& estimations, integration between/within \\
& professional groups, feedback effects between \\
& demand and supply, interaction with other \\
& goals, assessment of the outputs, etc. \\
& Aim of data collection, individual/aggregate \\
data, unique/multiple sources, comprehensive & information, updated database, etc. \\
Data & How the planning process is connected with \\
& the actions that will achieve what has been \\
planned, monitoring and controlling, etc. & Workflow, decentralization of planning \\
& responsibilities, stakeholder involvement, role \\
of the stakeholders, communication, staff \\
members, etc.
\end{tabular}

a According to the JAHWF 'Handbook on Health Workforce Planning Methodologies across EU countries'. 